\title{
BLANCHING OF THE SKIN BY SERUM INJECTION IN SCARLET FEVER
}

\author{
F. W. MUL SOW \\ From the John McCormick Institute for Infectious Diseascs, Chicago
}

In the treatment of scarlet fever with serum from convalescents of scarlet fever, Schultz and Charlton ${ }^{1}$ observed, the day following the injection of the serum, that the rash had faded around the point of injection. This blanching appeared to extend farthest along the lymphatics. They also found, by injecting intracutaneously from 0.5 to $1 \mathrm{c} \mathrm{c}$ of serum from normal persons or convalescents of scarlet fever, that there was a blanching of the rash for a distance of $1 \mathrm{~cm}$. around the point of injection. This blanching was somewhat irregular in outline, appeared from 6 to 8 hours after the injection and persisted unti' the general rash had faded. The serums from several other animals did not produce such blanching.

Neumann ${ }^{2}$ obtained similar results, and in addition, he found that rashes from other causes, which resemble that in scarlet fever, were not extinguished by convalescent or normal serum. He also found that the serums from cases of diphtheria, measles and other exanthems reacted in the same way as normal serum, but that the serum from scarlet fever patients in the first four days of the disease did not produce the blanching. From these observations Neumann concludes that the blanching phenomenon may be a valuable aid in the differential diagnosis of scarlet fever.

Schultz ${ }^{3}$ more recently has confirmed the work of Neumann and his own earlier findings, and states that blanching occured in $100 \%$ of the cases when the injections were made on the second day of the rash, in $78 \%$ of 14 cases injected the third day of the rash, in $60 \%$ of 5 cases each, injected on the first and fourth day of the rash, and in no case when injected on the fifth day. It is interesting to note that the results are as variable when injections are made on the first day as on the fourth day.

Tron, ${ }^{4}$ making similar injections with human serums from various sources in 50 scarlet fever patients, concludes that the blanching phe-

Received for publication July 8, 1921.

1 Ztschr. f. Kinderheilkunde, 1918, 17, p. 328.

2 Deutsch, med. Wchnschr., 1920, 46, p. 566.

3 Acta. med. Scand., 1921, 54, p. 49.

4 Riforma med., 1921, 57, p. 55. 
nomenon has little diagnostic value, since blanching occurred in only $26 \%$ of injections made with serums other than those from acute cases of scarlet fever. He confirms, however, the results of the previous investigators in that the serum from scarlet fever patients during the first few days of the disease does not produce the blanching.

In my work blood was drawn from convalescent. scarlet fever patients from 21 to 28 days after the appearance of the rash and from the acutely ill during the first 4 days of the rash. The serum was drawn off after the blood had been at icebox temperature for from 10 to 18 hours. The Wassermann and sterility tests were then made and the serum, placed in $1 \mathrm{c} \mathrm{c}$ vials, heated at 56 degrees for an hour, and stored in the icebox for as long as 2 months in some instances. It was soon found that the unheated serum reacted in the same way as the heated serum, hence many of the more recent tests have been made with unheated serum. Schultz and Tron also observed that heating of the serum did not influence its action. From 0.5 to $1 \mathrm{cc}$ of the serum was injected intracutaneously into scarlet fever patients during the first 4 days of the eruption. Injections were made in the lower chest region, abdominal wall or thigh. Samples of serum from an acute case of scarlet fever and from a normal person or scarlet fever convalescent were injected at the same time and in the same general region. In some instances as many as 5 injections were made in a patient at one time.

The blanching of the rash in scarlet fever that follows the intracutaneous injection of serum from normal persons or convalescents from scarlet fever, is usually quite definite and involves on an average a circular area about $2.5 \mathrm{~cm}$. in diameter. In some instances, however, the area is as large across as $5 \mathrm{~cm}$. with a very irregular outline, while in other cases it is only $1 \mathrm{~cm}$. across and quite regular. When the blanching is definite it persists until the general rash fades, but in some cases it is only slightly perceptible and soon disappears entirely. The outline of the blanched area is rather irregular but quite definite although frequently the change from the faded area to the surrounding rash is gradual and the border indefinite.

The intracutaneous injection of convalescent serum into scarlet fever patients during the first 4 days of the rash produced definite blanching around the point of injection in $53 \%$ of the cases and slight or questionable blanching in $10 \%$. The injection of normal serum produced definite blanching in $40 \%$ and slight blanching in $15 \%$ of the cases. The injection of serum drawn from scarlet fever patients during 
the first four days of the eruption did not produce blanching, except in one instance in which there was a slight or questionable fading of the rash around the point of injection. Often when definite blanching occurred there was a slight redness of the skin where the wheal-like lesions was made during the injection. Storing the serums in the icebox for as long as 2 months apparently did not affect their activity. There was no blanching of the rash in a case of rubella or in the scarlatinoid eruption following the administration of antitoxin when serum from a normal man and from 2 convalescents from scarlet fever was injected. The serum from the case of rubella produced slight blanching in 1 of 3

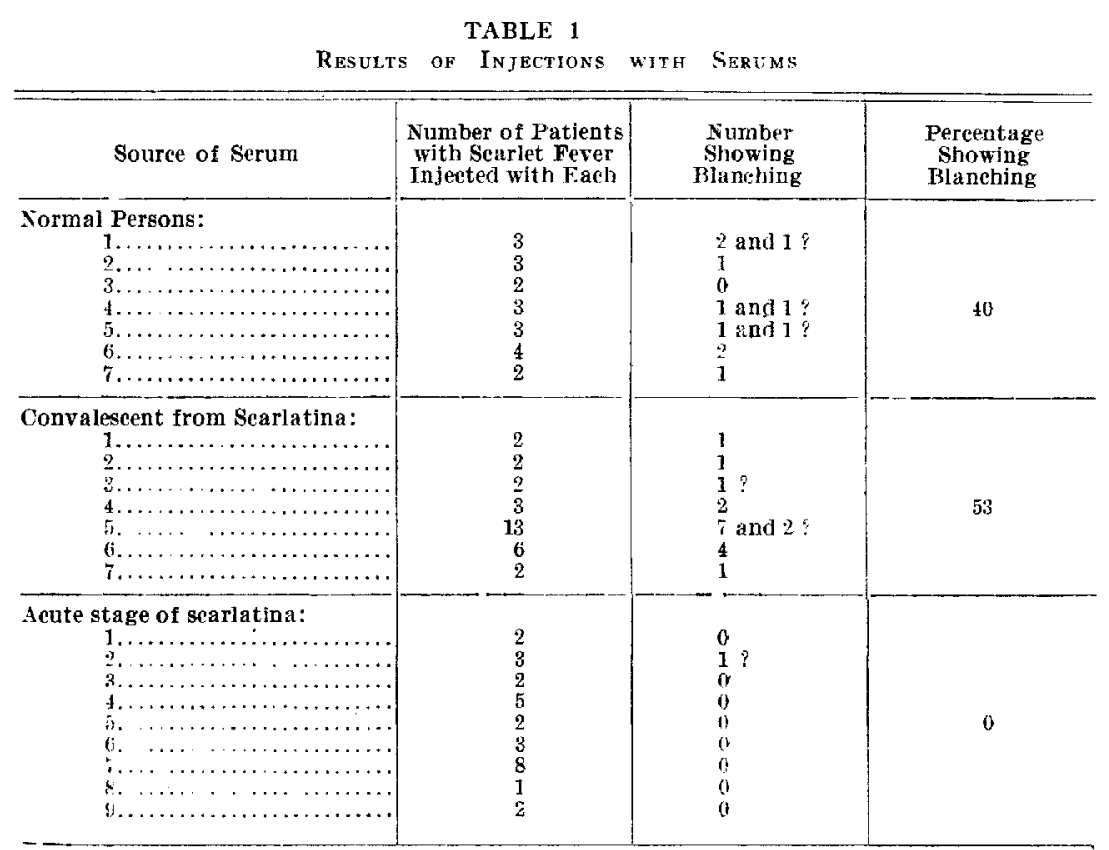

injections made in scarlet fever rashes; it caused a ceaction, however, the same as serums from 2 scarlet fever convalescents except that one of the latter produced a more marked blanching in the one case where blanching occurred. The table shows the injections and the results in cases of scarlet fever.

\section{SUMMARY}

While definite conclusions cannot be made from so few observations, it appears that the serum from those acutely ill with scarlet fever rarely produces any blanching effect. The serum from normal persons or 
scarlet fever convalescents produces quite a definite blanching in approximately $50 \%$ of the cases; there was a taint suggestion of blanching in $12 \%$ of the whole number and an entire absence of any blanching in the rest. In considering the practical applications of this test it must be recalled that when the rash is rather faint or fading, blanching cannot be observed. In general, if no blanching occurs when serum is injected into a patient in the acute stage of scarlet fever, the results would mean little, but should blanching occur it would appear that the injected serum is not from a scarlet fever patient in the acute stage of the disease. Although the blanching phenomenon is interesting from the scientific standpoint, it does not appear at present to be of signal value in the differential diagnosis of scarlet fever. 